\title{
Impact of routine PCV7 (Prevenar) vaccination of infants on the clinical and economic burden of pneumococcal disease in Malaysia
}

\author{
Syed Aljunid ${ }^{1,2^{*}+}$, Gulifeiya Abuduxike ${ }^{1 \dagger}$, Zafar Ahmed ${ }^{2 \dagger}$, Saperi Sulong ${ }^{2+}$, Amrizal Muhd Nur $^{2+}$ and Adrian Goh ${ }^{3+}$
}

\begin{abstract}
Background: Pneumococcal disease is the leading cause of vaccine-preventable death in children younger than 5 years of age worldwide. The World Health Organization recommends pneumococcal conjugate vaccine as a priority for inclusion into national childhood immunization programmes. Pneumococcal vaccine has yet to be included as part of the national vaccination programme in Malaysia although it has been available in the country since 2005. This study sought to estimate the disease burden of pneumococcal disease in Malaysia and to assess the cost effectiveness of routine infant vaccination with PCV7.

Methods: A decision model was adapted taking into consideration prevalence, disease burden, treatment costs and outcomes for pneumococcal disease severe enough to result in a hospital admission. Disease burden were estimated from the medical records of 6 hospitals. Where local data was unavailable, model inputs were obtained from international and regional studies and from focus group discussions. The model incorporated the effects of herd protection on the unvaccinated adult population.

Results: At current vaccine prices, PCV7 vaccination of 90\% of a hypothetical 550,000 birth cohort would incur costs of RM 439.6 million (US\$128 million). Over a 10 year time horizon, vaccination would reduce episodes of pneumococcal hospitalisation by 9,585 cases to 73,845 hospitalisations with cost savings of RM 37.5 million (US\$10.9 million) to the health system with 11,422.5 life years saved at a cost effectiveness ratio of RM 35,196 (US\$10,261) per life year gained.
\end{abstract}

Conclusions: PCV7 vaccination of infants is expected to be cost-effective for Malaysia with an incremental cost per life year gained of RM 35,196 (US\$10,261). This is well below the WHO's threshold for cost effectiveness of public health interventions in Malaysia of RM 71,761 (US\$20,922).

\section{Background}

Streptococcus pneumoniae (S. pneumoniae) is a bacterial pathogen responsible for significant morbidity and mortality worldwide, particularly in young children and the elderly [1-4]. Non-invasive pneumococcal disease is caused by $S$. pneumoniae infection of mucosal tissue, such as the upper respiratory tract, middle ear and sinuses which can lead to non-bacteraemic pneumonia, acute otitis media $(\mathrm{OM})$ and sinusitis. The more severe invasive pneumococcal disease (IPD) occurs when bacteria disseminates into

\footnotetext{
* Correspondence: syed.aljunid@unu.edu

+ Contributed equally

'United Nations University-International Institute For Global Health, Kuala

Lumpur, Malaysia

Full list of author information is available at the end of the article
}

the bloodstream and central nervous system resulting in bacteraemia, meningitis, and bacteraemic pneumonia [5-8]. It is estimated that up to one million children under 5 years of age die every year from pneumococcal pneumonia, meningitis and sepsis $[9,10]$. Data from the World Health Organization (WHO) shows that pneumococcal disease is the leading cause of vaccine-preventable death in children younger than 5 years of age worldwide [11]. In 2009 , pneumonia was the $4^{\text {th }}$ leading cause of death in Ministry of Health (MOH) Hospitals in Malaysia with $10.4 \%$ of hospital mortality while respiratory diseases were the $3^{\text {rd }}$ leading cause of hospitalisation with $9.4 \%$ of discharges [12].

Although antibiotic treatment for pneumococcal diseases are available, there are still unmet medical needs 
as reflected in the mortality and morbidity data. Prevention via vaccination is an important intervention that could reduce the incidence of pneumococcal infection and its complications [5]. One of the available vaccines in Malaysia at the time of this study was Prevenar ${ }^{\circledR}$, a Heptavalent Pneumococcal Conjugate Vaccine (PCV7), indicated for the active immunization of infants and children from 6 weeks through 9 years of age. Prevenar contains saccharides of the capsular antigen of S. pneumoniae serotypes $4,6 \mathrm{~B}, 9 \mathrm{~V}, 14,18 \mathrm{C}$, $19 \mathrm{~F}$ and $23 \mathrm{~F}$ individually conjugated to the diphtheria Cross Reactive Material 197 (CRM197) protein [13]. Following recommendation by the Strategic Advisory Group of Experts (SAGE) on immunization, the World Health Organization considers that the pneumococcal conjugate vaccine should be a priority for inclusion in national childhood immunization programmes [6]. As of January 2010, high pneumococcal vaccination coverage has been achieved in 43 countries as part of national immunization programmes or through other means [14]. PCV7 has been available in Malaysia since 2005 but has yet to be included in the national vaccination programme.

The herd effect, also known as herd immunity, is defined as the reduction of infection or disease in the unimmunised segment as a result of immunising a proportion of the population [15-17]. This effect is seen in vaccination with PCV7, where it has been shown to be able to reduce nasopharyngeal carriage of vaccine strains in immunised children, resulting in subsequent interruption of transmission to unimmunised contacts [18]. In countries where PCV7 has been included as part of the routine vaccination schedule, surveillance data has demonstrated that vaccination of specific populations not only provides immunised individuals with protection against pneumococcal disease, but also reduces the risk of developing pneumococcal illness in unimmunised individuals.. For example, in the United States, it is estimated that PCV7 has prevented more than twice as many cases of pneumococcal disease through indirect effects [19]. Another study from 8 states across the United States reported a $28 \%$ reduction in incidence of pneumococcal disease and a $55 \%$ reduction in conjugate vaccine serotypes in adults above 50 years of age after the introduction of PCV7 infant vaccination in year 2000 [20]. A study of households in Pennsylvania also found an $80 \%$ reduction $(\mathrm{OR}=0.2,95 \%$ CI $0.1-0.8)$ in the odds ratio of bacteraemic pneumococcal pneumonia among adults in households where young children had received PCV7 vaccination [21].

This study sought to estimate the disease burden of pneumococcal disease in Malaysia and to assess the cost effectiveness of routine infant vaccination with PCV7.

\section{Methods}

A decision analytic model based on PCV7 immunization in the United Kingdom by McIntosh [22] was adapted to determine the effects and cost effectiveness of universal infant PCV7 vaccination compared with no vaccination for a hypothetical birth cohort of 550,000 infants over a 10-year time horizon. Similar to McIntosh, the model incorporated hospitalised cases of pneumococcal disease based on age-specific disease incidence rates. These included pneumococcal meningitis, pneumococcal septicaemia and pneumococcal pneumonia as well as a proportion of unspecified pneumonia and otitis media. All cases of pneumococcal infections requiring hospitalisation from pre-admission to post-admission follow-ups in the outpatient setting were included. Demographic assumptions within the model are described in Table 1. The analysis was performed from the payer perspective.

This study was approved by the ethics committees of the National University of Malaysia (FF-12-2008) and the Ministry of Health Malaysia (NMRR-08-664-1819).

\section{Disease incidence estimation}

The incidence of hospitalised pneumococcal disease was estimated from review of medical records from 20062007 at six tertiary hospitals. These six hospitals were selected to broadly represent Malaysia geographically as shown in Table 2.

Cases of hospitalised pneumococcal disease were primarily identified by International Statistical Classification of Diseases and Related Health Problems 10th Revision (ICD-10) classification at discharge. Additional patients positive for streptococcus pneumonia were also identified through review of laboratory records to ensure more comprehensive data capture. For the purpose of this study, ICD-10 pneumococcal disease codes included were: pneumococcal meningitis (code G00.1), pneumococcal septicaemia (code A40.3), and pneumonia due to S. pneumonia (code J13). In addition, the study identified other unspecified pneumonia (codes J15.9, J18, J18.9) and otitis media (codes H65, H66, H67). Thirty percent of all-cause pneumonia cases and $36 \%$ of meningitis and bacteraemia were attributed to S. pneumoniae [22-24]. All patient data was de-identified prior to analysis.

The incidence of pneumococcal disease by clinical presentation for children and adults in each hospital catchment area was calculated from epidemiological data from the six hospitals. Due to lack of any published estimates, assumptions about the population catchment and treatment provision by hospitals were obtained from a focus group discussion consisting of experienced clinicians and paramedics conducted in October 2008. The catchment population of UKM Medical Centre was assumed to be the entire population of the local district 
Table 1 Model assumptions on pneumococcal disease and vaccination effects

\begin{tabular}{|c|c|c|}
\hline Parameter & Value & Source \\
\hline \multicolumn{3}{|l|}{ Population distribution } \\
\hline Birth cohort & 550,000 & {$[25,26]$} \\
\hline 20-39 years age group & $8,770,937$ & {$[25,26]$} \\
\hline 40-64 years group & $5,536,238$ & {$[25,26]$} \\
\hline$\geq 65$ years group & $1,051,371$ & {$[25,26]$} \\
\hline Life expectancy at birth (years) & 74.2 & {$[30]$} \\
\hline PCV7 vaccine coverage & 495,000 & $90 \%$ of birth cohort [12] \\
\hline PCV7 vaccine compliance & $100 \%$ & \\
\hline \multicolumn{3}{|l|}{ Pneumococcal disease incidence } \\
\hline S. pneumonia isolated & $100 \%$ & \\
\hline Unspecified meningitis and bacteraemia & $36 \%$ & [24] \\
\hline All cause pneumonia & $30 \%$ & [23] \\
\hline \multicolumn{3}{|l|}{ Paediatric fatality rate } \\
\hline Meningitis & 0.2 & [31] \\
\hline Bacteraemia & 0.1 & {$[31]$} \\
\hline All cause pneumonia & $0 \%$ & {$[31]$} \\
\hline Otitis media & $0 \%$ & {$[31]$} \\
\hline \multicolumn{3}{|l|}{ Adult fatality rate } \\
\hline Meningitis & $9.0 \%$ & {$[32]$} \\
\hline Bacteraemia & $4.6 \%$ & [32] \\
\hline All cause pneumonia & $0.17 \%$ & {$[32]$} \\
\hline Otitis media & $0 \%$ & {$[32]$} \\
\hline PCV7 serotype coverage & $66.7 \%$ & {$[28]$} \\
\hline \multicolumn{3}{|l|}{ PCV7 efficacy in infants } \\
\hline Pneumococcal meningitis & $97.4 \%$ & {$[27]$} \\
\hline Pneumococcal bacteraemia & $97.4 \%$ & {$[27]$} \\
\hline All cause pneumonia & $6 \%$ & [27] \\
\hline Otitis media & $7 \%$ & {$[27]$} \\
\hline \multicolumn{3}{|c|}{ PCV7 efficacy decline over time (efficacy waning) } \\
\hline$\leq 5$ years post-vaccination & $1 \%$ р.а. & [22] \\
\hline $6-10$ years post-vaccination & $3 \%$ р.а. & {$[22]$} \\
\hline \multicolumn{3}{|l|}{ Reduction on IPD in adults (herd effects) } \\
\hline 20-39 years group & $32 \%$ & [29] \\
\hline 40-64 years group & $8 \%$ & [29] \\
\hline$\geq 65$ years group & $18 \%$ & [29] \\
\hline
\end{tabular}

and $30 \%$ of the population in the neighbouring district. The catchment area for the remaining five hospitals was assumed to be the entire 2007 population of the urban area and $5 \%$ of the state population where the hospitals were located [25,26]. Each hospital was assumed to provide treatment for $50 \%$ of cases within its catchment area. The national incidence rate by age group and presentation in 2007 was estimated as the average disease rate across the six hospitals. The incidence rate was varied in sensitivity analysis.

Table 2 Primary sources of epidemiological data

\begin{tabular}{llc}
\hline Hospital & Type of Hospital & \multicolumn{1}{c}{$\begin{array}{c}\text { Region } \\
\text { (\% national population) }\end{array}$} \\
\hline National University of Malaysia Medical Centre & Teaching hospital & Kuala Lumpur, Central Peninsula \\
Hospital Tuanku Jaafar, Seremban & Ministry of Health & Seremban, Central Peninsula \\
Hospital Universiti Sains Malaysia & Teaching hospital & Kota Bharu, Peninsula East Coast \\
Hospital Tengku Ampuan Afzan, Kuantan & Ministry of Health & Kuantan, Peninsula East Coast \\
Hospital Sultanah Bahiyah, Alor Setar & Ministry of Health & Alor Setar, Northern Peninsula \\
Sarawak General Hospital & Ministry of Health & Kuching, East Malaysia
\end{tabular}




\section{Vaccine efficacy}

Vaccine efficacy in the target population is assumed to be 97.4\% against pneumococcal meningitis and pneumococcal bacteraemia, $6 \%$ against all-cause pneumonia and 7\% against otitis media in line with the Northern California Kaiser Permanente (NCKP) study [27]. Serotype coverage was adjusted to $66.7 \%$ based on the results of a local survey to account for potential differences in the serotype landscape in Malaysia relative to the NCKP trial [28].

Vaccination was assumed to be administrated in 4 doses at 2, 4, 6 and 12 to 15 months of age with efficacy commencing from the $1^{\text {st }}$ dose. PCV7 vaccination coverage is assumed at $90 \%$ of the birth cohort as the coverage of most vaccinations under the existing Malaysian national immunisation programme exceeds 95\% [12]. A 100\% compliance rate (i.e. that all infants in the cohort would to complete all 4 doses of vaccination) was assumed in order to reduce model complexity.

Consistent with previous economic studies on PCV7, the efficacy of PCV7 in the vaccinated birth cohort is assumed to decline by $1 \%$ per year up to the age of 5 years and by $3 \%$ per year from 6 to 10 years of age [22].

The effect of herd protection in the unvaccinated population is incorporated into the model by assuming reduction in the incidence of inpatient IPD by $32 \%$ in the $20-39$ years group, $8 \%$ in the $40-64$ years group and $18 \%$ in the $\geq 65$ years group respectively [29]. The model assumptions on vaccine effects are described in Table 1.

\section{Outcomes estimation}

Population data and life expectancy were based on 2006 population estimates for the various age cohorts in Malaysia. The life expectancy for infants was estimated to be 74.2 years [30] and the birth cohort was estimated to be 550,000 infants. The national population distribution by age group was $8,770,937$ in the $20-39$ years age group, 5,536,238 in the 40-64 years group and 1,051,371 in the greater than 65 years group [30]. Due to the absence of local age-specific mortality data, rates for paediatric and adult fatality were adopted from Singapore and Hong Kong respectively [31,32]. These assumptions are described in Table 1.

\section{Cost estimation}

The cost of pneumococcal disease was determined from the perspective of the Malaysian healthcare system. These included the costs of direct medical resources including costs of physician consultation, all drugs consumed during admission and follow-up episodes, hospitalisation, diagnostic tests and surgical interventions. The treatment of an episode of pneumococcal disease covered the period from pre-admission care to hospitalisation and post-dis- charge out-patient follow-up. The costs of outpatient treatment that was not linked to any hospital admission were excluded.

Resources used in outpatient pre-admission and postdischarge treatment were estimated by the focus group discussion. The focus group delineated clinical pathways of treatment for pneumococcal disease which was then used to identify resources consumed to treat various clinical presentations.

Unit costs used in this analysis are shown in Table 3. These were obtained by a top-down costing approach to estimate cost of treatment in each hospital using the Clinical Costing Software Version 1.0 (CCM Ver. 1.0) developed by the Case-Mix Unit of the UKM Medical Centre. The software estimates unit costs for inpatient and outpatient treatment by distributing costs into three levels beginning with overhead cost centres, followed by intermediate cost centres and finally patient cost centres. Within each level, costs are distributed according to allocation factors such as floor size, staff counts, patient counts and inpatient days. The aforementioned focus group estimated that patient care in the Malaysian healthcare setting would typically have 2 to 3 visits to outpatient care prior to hospitalisation for pneumococcal disease. Therefore, depending on the disease manifestation, pre-admission and post-discharge outpatient treatment costs vary for an episode of hospitalisation as shown in Table 3.

The following conventions were used for imputing capital and recurrent costs:

\section{Capital Cost}

Cost of buildings and fixtures have been included. The life span of buildings was estimated at 20 years with an annual depreciation of $5 \%$, costs of instruments, transportation/vehicles have been determined at a life span of 5 years with an annual depreciation of $20 \%$. Only areas and vehicles used within the activity scope of this study were considered.

\section{Recurrent Cost}

Recurrent costs included cost of labour and supplies. Labour costs included salaries, bonuses and allowances to healthcare personnel. Costs of supplies were calculated as the total cost of all purchases of medication and nonmedication items. Utility costs due to water, electricity supply, telephone and waste maintenance were calculated for each activity within the scope of the study.

Both costs and benefits are discounted at 3\% in the primary analysis. In sensitivity analysis costs were discounted at 3\% while benefits were not discounted [33].

All costs were measured in 2007 Malaysian Ringgit (RM). The 2007 average exchange rates of US $\$ 1$ to RM3.43 and $€ 1$ to RM4.71 were applied to currency conversions [34]. 
Table 3 Model assumptions on costs

\begin{tabular}{|c|c|c|}
\hline Cost Parameter & Value (RM) & Remarks \\
\hline PCV7 vaccination cost (per infant) & 888 & 4 dose regimen at current market price of RM222 per dose \\
\hline \multicolumn{3}{|l|}{ Pre-admission costs (adult and paediatric) } \\
\hline Meningitis, pneumonia and otitis media & 206 & Focus group discussion \\
\hline Septicaemia & 309 & \\
\hline \multicolumn{3}{|l|}{ Post-discharge costs (adult and paediatric) } \\
\hline Meningitis, pneumonia and otitis media & 309 & Focus group discussion \\
\hline Septicaemia & 1,236 & \\
\hline \multicolumn{3}{|c|}{ Paediatric cost per episode of hospitalised infection } \\
\hline Pneumococcal bacteraemia & 7,076 & \\
\hline Pneumococcal meningitis & 5,399 & \\
\hline Hospitalised all-Cause pneumonia & 2,592 & $\begin{array}{l}\text { Weighted average cost of treatment } \\
\text { for each episode of disease } \\
\text { calculated using data from } \\
6 \text { local hospitals }\end{array}$ \\
\hline Severe otitis media & 2,554 & \\
\hline Weighted cost per episode of IPD & 3,191 & \\
\hline \multicolumn{3}{|c|}{ Adult cost per episode of hospitalised infection } \\
\hline Pneumococcal bacteraemia & 6,141 & \\
\hline Pneumococcal meningitis & 3,504 & $\begin{array}{l}\text { Weighted average cost of treatment } \\
\text { for each episode of disease } \\
\text { calculated using data from } \\
6 \text { local hospitals }\end{array}$ \\
\hline Hospitalised all-Cause pneumonia & 2,830 & \\
\hline Weighted cost per episode of IPD & 3,768 & \\
\hline Discount rate on costs and outcomes & $3 \%$ & \\
\hline Building use life & 20 years & \\
\hline Building depreciation & $5 \%$ p.a. & \\
\hline Instrument and vehicle use life & 5 years & \\
\hline Instrument and vehicle depreciation & $20 \%$ p.a. & \\
\hline
\end{tabular}

Note: Costs are measured in year 2007 Malaysian Ringgit (RM).

\section{Costs effectiveness analysis}

A cost effectiveness model was used to estimate the impact of routine PCV7 vaccination of a birth cohort of 550,000 infants compared with no vaccination over a 10-year time horizon [22]. Model inputs included epidemiological and cost data from the six hospitals, focus group discussions and published sources as described above.

Cost-effectiveness was expressed as cost per life-year gained (LYG) where years of life are retained due to death avoided by means of an intervention, in this case universal infant vaccination. LYG was determined by taking into consideration average life expectancy minus the age of death due to IPD (LYG = Average life expectancy age of expected death). Therefore, LYG was calculated by Malaysian life expectancy (74.2 years) minus the child or adult's age at the time of death due to disease. The incremental cost per life year gained was calculated by comparing routine infant vaccination with PCV7 against the alternative of no routine vaccination.

\section{Sensitivity analysis}

Sensitivity analysis was conducted by reducing the cost from a four dose to three dose regimen. Based on results from other studies we assume no decline in efficacy from the dose reduction $[35,36]$. One way sensitivity analyses were also performed by varying the herd effects of vaccination [29], vaccine efficacy rates against paediatric cases of all-cause pneumonia and otitis media, and the serotype coverage of PCV7 [27,37]. Lastly, sensitivity analysis was performed by varying the discount rate on outcome to $0 \%$ (i.e. undiscounted outcome) while the maintaining a $3 \%$ discount on costs [33].

\section{Results}

\section{Diseases incidence}

Based on data from the six hospitals, the estimated agespecific incidence of hospitalised IPD, all-cause pneumonia and all-cause otitis media in Malaysia is as shown in Table 4. The highest rates of hospitalisation were 
Table 4 Age specific incidence of pneumococcal disease by presentation

\begin{tabular}{|c|c|c|c|c|c|}
\hline \multirow[t]{2}{*}{$\begin{array}{c}\text { Clinical } \\
\text { presentation }\end{array}$} & \multicolumn{5}{|c|}{$\begin{array}{c}\text { Annual incidence by age group and clinical presentation } \\
\text { (per } 1000 \text { population a) }\end{array}$} \\
\hline & $0-4$ & $5-19$ & 20-39 & $40-64$ & $\geq 65$ \\
\hline Pneumococcal meningitis & 0.347 & 0.057 & 0.035 & 0.027 & 0.046 \\
\hline Pneumococcal bacteraemia & 0.463 & 0.1 & 0.152 & 0.593 & 2.533 \\
\hline Pneumococcal pneumonia & 2.396 & 0.391 & 0.32 & 1.124 & 6.34 \\
\hline All-cause pneumonia & 7.658 & 1.261 & 0.933 & 3.525 & 20.406 \\
\hline All-cause otitis media & 0.491 & 0.337 & 0.152 & 0.294 & 0.165 \\
\hline
\end{tabular}

a Population data by age-group for each hospital catchment area for 2006-2007 was used as the denominator for calculation.

Source: Department of Statistics, Malaysia.

observed for all cause pneumonia in the elderly above 65 years of age at 20.406 hospitalisations per 1000 population and in children under 4 years of age at 7.658 per 1000 population.

\section{Costs}

At the proposed market price of RM222 per dose in a four dose regimen, a total vaccine cost of RM439.59 million would be incurred to vaccinate 495,000 infants, equivalent to $90 \%$ of the birth cohort of 550,000 as shown in Table 5. The direct medical cost of an episode of pneumococcal disease in a paediatric population varies from RM2,554 for an episode of hospitalised otitis media to RM7,076 for an episode of hospitalised pneumococcal septicaemia. The corresponding cost for adult care varies from RM2,830 for an episode of hospitalised all-cause pneumonia to RM6,141 for an episode of hospitalised pneumococcal septicaemia as shown in Table 3.

\section{Table 5 Outcomes and cost effectiveness}

\begin{tabular}{|c|c|c|c|}
\hline & $\begin{array}{c}\text { No } \\
\text { vaccination }\end{array}$ & $\begin{array}{c}\text { PCV7 } \\
\text { vaccination }\end{array}$ & Incremental \\
\hline \multicolumn{4}{|l|}{ Hospitalised cases (n) } \\
\hline Total & 83,430 & 73,845 & $-9,585$ \\
\hline Paediatric & 51,933 & 47,459 & $-4,474$ \\
\hline Adult & 31,497 & 26,386 & $-5,111$ \\
\hline \multicolumn{4}{|l|}{ Deaths (n) } \\
\hline Total & 1,074 & 666 & -408 \\
\hline Paediatric & 639 & 303 & -336 \\
\hline Adult & 435 & 363 & -72 \\
\hline \multicolumn{4}{|l|}{ Life Years Lost (years) } \\
\hline Total & $26,154.00$ & $14,731.60$ & $-11,422.50$ \\
\hline Paediatric & $19,482.60$ & $9,239.90$ & $-10,242.70$ \\
\hline Adult & $6,671.40$ & $5,491.60$ & $-1,179.80$ \\
\hline \multicolumn{4}{|l|}{ Costs (RM million) } \\
\hline Total & 255.8 & 657.9 & 402 \\
\hline Vaccine & 0 & 439.6 & 439.6 \\
\hline Hospitalisation episodes & 255.8 & 218.3 & -37.5 \\
\hline Paediatric & 137.2 & 118.9 & -18.3 \\
\hline Adult & 118.7 & 99.4 & -19.3 \\
\hline ICER (per life year gained) & & & $\begin{array}{c}\text { RM35,196 } \\
(\text { US\$10,261) }\end{array}$ \\
\hline
\end{tabular}

\section{Outcomes}

As shown in Table 5 over the 10-year time horizon of the model, vaccination of the birth cohort is estimated to prevent 4,474 cases of paediatric hospitalisations. These included 2,036 cases of IPD (consisting of 1,538 cases of bacteraemia and 498 meningitis), 2,289 cases of all-cause pneumonia and 149 cases of severe otitis media. Vaccination would also save 336 lives by reducing paediatric mortality from 639 to 303 deaths with 10,242.7 life years gained. With the addition of herd effects, a further 5,111 hospitalised cases of IPD and 72 deaths in adults would be avoided with 1,179.8 years of life saved.

\section{Cost effectiveness}

Our model estimates that without vaccination, pneumococcal disease hospitalisations cost the health system approximately RM256 million (US\$74.6 million) over 10 years. Routine infant vaccination will reduce hospitalisation costs by RM 37.5 million, to RM218.3 million over the same period.

Comparing routine infant vaccination with no vaccination over a 10 year time horizon, vaccination gains 11,422.5 life years at an additional cost of RM402 million. Thus, routine infant PCV7 vaccination incurs an incremental cost (ICER) of RM 35,196, (US\$10,261) per life year gained (LYG) if herd protection in the adult population is included as shown in Table 5.

WHO guidelines on generalized cost-effectiveness analyses for public health interventions considers programmes to be cost effective when the cost-effectiveness ratio is between one and three times the country's GDP per capita [38]. As Malaysia's GDP per capita was RM23,920 (US $\$ 6,974$ ) in 2007 [34], an ICER of RM 35,196 for routine PCV7 vaccination would be considered cost effective as it is well within Malaysia's cost effectiveness threshold of RM71,761 (US\$20,922).

\section{Sensitivity Analyses}

As shown in Table 6 the model ICER results were sensitive to variations in the number of doses of PCV7, the incidence rate of meningitis and septicaemia, and the efficacy of the vaccine against IPD. Varying the dose 
Table 6 Sensitivity analysis

\begin{tabular}{|c|c|c|}
\hline Model parameters & Range of values & ICER (RM) \\
\hline Dose regimen & $3-4$ doses & $25,576-35,196$ \\
\hline \multicolumn{3}{|l|}{ Herd effects } \\
\hline \multicolumn{3}{|l|}{ Lower $95 \%$ bound on herd effects } \\
\hline Age $20-30$ & $23 \%$ & 37,648 \\
\hline Age 40-64 & $1 \%$ & \\
\hline Age $\geq 65$ & $11 \%$ & \\
\hline \multicolumn{3}{|l|}{ Higher herd effects } \\
\hline Age $20-30$ & $41 \%$ & 31,886 \\
\hline Age $40-64$ & $20 \%$ & \\
\hline Age $\geq 65$ & $31 \%$ & \\
\hline Discounting of costs (benefits not discounted) & $3 \%$ & 33,140 \\
\hline Vaccine serotype coverage & $61.7-71.7 \%$ & $34,208-36,242$ \\
\hline$\%$ cohort vaccinated & $80-100 \%$ & $31,711-32,751$ \\
\hline \multicolumn{3}{|l|}{ Vaccine efficacy } \\
\hline IPD & $82.7 \%$ to $99.9 \%$ & $34,377-40,896$ \\
\hline Pneumonia & $-1.5 \%$ to $11 \%$ & $34,802-35,788$ \\
\hline Otitis Media & $4.1 \%$ to $9.7 \%$ & $35,184-35,209$ \\
\hline \multicolumn{3}{|l|}{ Disease incidence } \\
\hline Meningitis & & $26,703-41.777$ \\
\hline Bacteraemia & $\begin{array}{l}50 \% \text { to } 200 \% \\
\text { of base case }\end{array}$ & $21,629-50,437$ \\
\hline Pneumonia & & $34,723-35,433$ \\
\hline Otitis Media & & $35,166-35,212$ \\
\hline
\end{tabular}

regimen to 3 doses results in ICER of RM25,576 per LYG. Varying other model parameters such as herd effects on the adult population, the vaccine serotype coverage, cohort vaccination rate, vaccine efficacy or disease incidence did not result in the ICER exceeding Malaysia's cost effectiveness threshold of RM71,761.

\section{Discussion}

The results from the cost-effectiveness analysis show that routine infant vaccination with PCV7 can lead to a reduction in the incidence of all manifestations of pneumococcal disease and potentially save lives. In the paediatric population, universal vaccination is estimated to prevent 4,474 hospitalisations over a 10 -year period. When the analysis included the impact of herd protection on the adult population, an additional 5,111 cases of hospitalised IPD and 72 deaths are estimated to be prevented.

At an ICER of RM 35,196 per LYG, the result of this study compares favourably against the WHO's recommended cost effectiveness threshold for Malaysia of RM71,761 as well as another large publically funded health programme in Malaysia that is the MOH chronic haemodialysis programme which has reported CER of RM33,642 in 2001 (equivalent to RM38,240 in 2007 after adjusting for general inflation) [39,34].
A meta-analysis by Isaacman examined the cost effectiveness of Prevenar vaccination in several countries as shown in Table 7 [40]. Similar to the current study, the studies included were based on similar assumptions of 4 doses of vaccine administered, 10-year model timeline, 10 -year vaccine protection, and cost and benefits discounted at $3 \%$ per year. They showed that the costeffectiveness evidence for PCV7 supported the initiation of national immunization programs in countries considered. The cost effectiveness ratio of our study (at RM35,196 or $€ 7,479$ per LYG) appears to be comparable to studies evaluated by Isaacman. However, such direct comparisons should be made cautiously as this present study has methodological differences to those considered in Isaacman's review. Specifically, the current study did not consider long-term cost savings from pneumococcal sequelae avoided and other outpatient cost savings.

The results of this study support the implementation of a nationwide programme of infant vaccination. We employed highly conservative incidence rates of pneumonia and otitis media in the paediatric population as only hospitalised (i.e. severe cases) were included in the model. The cost of pneumococcal disease treated exclusively in the outpatient setting was not included due to lack of reliable epidemiological and costing data. Our 
Table 7 International comparisons of the cost-effectiveness of PCV7 (Source: Isaacman et al. 2008)

\begin{tabular}{|c|c|c|}
\hline Author (Year), Country & Total Vaccine Cost per dose, $€^{*}$ & $\begin{array}{l}\text { Cost-Effectiveness } \\
\text { (Payer perspective), } €\end{array}$ \\
\hline $\begin{array}{l}\text { McIntosh et al (2005) } \\
\text { United Kingdom }\end{array}$ & $€ 89.33$ & $€ 4,767$ per LYG \\
\hline $\begin{array}{c}\text { Melegaro and Edmunds (2004) } \\
\text { United Kingdom }\end{array}$ & $€ 72.55$ & $€ 9,607$ per LYG \\
\hline $\begin{array}{c}\text { Ray et al }(2006)^{\S} \\
\text { United States }\end{array}$ & $€ 51.72$ & $€ 14,750$ per LYG \\
\hline $\begin{array}{c}\text { Wisløf et al (2006)^ } \\
\text { Norway }\end{array}$ & $€ 56.30$ & $€ 159,503$ per LYG \\
\hline
\end{tabular}

*Includes administration costs and costs of adverse events. Costs were converted to euros.

${ }^{\Phi}$ Costs were discounted $6 \%$, benefits $0 \%$.

\# IPD rates were adjusted to reflect serotype distribution in the United Kingdom. Vaccine efficacy was $63 \%$ to $87 \%$ for the first 5 years. A lifetime analysis was performed, and a 3-dose schedule was used. Pneumococcus was responsible for $48 \%$ of pneumonia cases.

${ }^{\S}$ Vaccine efficacy was $2.7 \%$ to $3.2 \%$ for simple otitis media, $14.4 \%$ to $16.9 \%$ for complex otitis media, and $59 \%$ to $72 \%$ for IPD. The indirect effect did not include the effect on pneumonia or otitis media.

$\wedge$ Indirect effects were modified to reflect serotypes in Norway: $8.9 \%$ in those aged 20 to 39 years; $12.9 \%$ in those aged 40 to 64 years; and $22.9 \%$ in those aged $\geq 65$ years.

results do not estimate the true burden of disease seen in the community which are treated in the outpatient setting and therefore underestimates cost effectiveness. This can be regarded as a limitation since cost savings from reduction of pneumococcal disease treated in outpatient settings are likely to be considerable.

If the burden of disease in outpatients were also included in the model, the results would likely show greater cost effectiveness from outpatient pneumonia and otitis media cases prevented. Other potential effects of vaccination on related clinical presentations of pneumococcal disease such as sinusitis and septic arthritis were not included in the analysis. The analysis also did not consider the effects or cost consequences of long term sequelae (deafness, brain damage, focal neural deficit and chronic seizures) on paediatric survivors of pneumococcal meningitis.

We note that there were several other limitations to this study. Firstly, there was limited local data upon which to base estimates and thus assumptions based on international sources and clinician focus group discussion were necessary. This included the assumptions about hospital catchment and treatment populations. Secondly, the implementation of ICD coding varies across Malaysian hospitals affecting our ability to capture all cases through ICD codes alone. To avoid underestimating the pneumococcal disease incidence in Malaysia using ICD-10 only, patients were also identified by review of laboratory records.

Thirdly, the analysis excluded the programmatic costs that would be incurred in implementing a national vaccination programme. Finally, the model also assumes the indirect benefits in reduced hospitalisations are accrued from the vaccination of a single cohort only although it may be debatable if herd effects can be fully realized from vaccination of a single cohort only.
Reduction of antibiotic resistance is another factor favouring implementation of pneumococcal vaccination. Data from the U.S. suggests significant reductions in antibiotic prescribing for paediatric cases of otitis media have occurred following licensing of PCV7 [37]. Similarly, a reduction in the incidence of antibiotic-non-susceptible IPD has also been reported, and has been attributed to widespread PCV7 vaccination [41]. This potential benefit is of significant importance in Malaysia where S. pneumoniae isolates have exhibited increased antibiotic resistance.

Since this study was conducted, newer pneumococcal vaccines with wider serotype coverage such as PCV13 have since become available. Nevertheless, the analysis presented in this study shows clearly that even with the narrow serotype coverage from PCV7, routine infant vaccination is cost effective. Further analysis based on newer pneumococcal vaccines such as PCV13 would demonstrate even better cost effectiveness as the protection afforded from vaccination would be even greater than with PCV7.

\section{Conclusions}

The results presented here show that universal infant vaccination with PCV7 has an incremental cost per life year gained of RM 35,196 (US\$10,261) when only direct costs of hospitalisation and the impact of herd protection in the unvaccinated adult population are included. These cost savings from both the direct and indirect effects of vaccination show that a national infant vaccination programme with PCV7 is a cost-effective intervention for Malaysia. Thus, it can be considered a worthwhile investment for protection of the population against pneumococcal disease.

\section{Acknowledgements}

We wish to thank the Director General of Health, Malaysia for permission to publish this paper. We would like to thank Drs Hasniah Abdul Latiff and 
Fauzi Mohd. Anshar of UKM Medical Centre, Drs Mohd Suhaimi Ab. Wahab and Shaharuddin Abdullah of Hospital Universiti Sains Malaysia, Dr. Chin Choy Nyok and Dato' Dr. Haji Sapari Satwi of Hospital Tengku Ampuan Afzan, Dato' Dr. Teh Keng Hwang and Dr. Mustafa Kamal Razak of Hospital Sultanah Bahiyah, Alor Setar, Drs Tan Kah Kee and Vijiya Mala of Hospital Tuanku Ja'afar, Seremban, and Drs Chan Lee Gaik and Kalwinder Singh Khaira of Sarawak General Hospital for their assistance during primary data collection. The preparation and publication of this manuscript was funded by a grant from Pfizer (M) Sdn Bhd.

\section{Author details}

'United Nations University-International Institute For Global Health, Kuala Lumpur, Malaysia. ${ }^{2}$ International Case-Mix and Clinical Coding Centre, UKM Medical Centre, Faculty of Medicine, University Kebangsaan Malaysia, Kuala Lumpur, Malaysia. ${ }^{3}$ Azmi Burhani Consulting, Kelana Jaya, Malaysia.

\section{Authors' contributions}

SA conceived the study, participated in its design, participated in primary data collection, participated in project coordination and helped to draft the manuscript. GA participated in the design of the study, participated in primary data collection, conducted the epidemiological analysis and helped to draft the manuscript. ZA participated in primary data collection, participated in the epidemiological analysis and helped to draft the manuscript. SS participated in the participated in the design of the study, participated in primary data collection, participated in the epidemiological analysis and helped to draft the manuscript. AMN participated in primary data collection, performed the cost analysis and helped to draft the manuscript. AG participated in the analysis and helped to draft the manuscript. All authors have read and approved the final manuscript.

\section{Competing interests}

The authors declare that they have no competing interests.

Received: 19 April 2011 Accepted: 21 September 2011 Published: 21 September 2011

\section{References}

1. Hausdorff WP, Bryant J, Paradiso PR, Siber GR: Which pneumococcal serogroups cause the most invasive disease: implications for conjugate vaccine formulation and use, part I. Clin Infect Dis 2000, 30:100-121.

2. Isaacman DJ, McIntosh ED, Reinert RR: Burden of invasive pneumococcal disease and serotype distribution among Streptococcus pneumoniae isolates in young children in Europe: impact of the 7-valent pneumococcal conjugate vaccine and considerations for future conjugate vaccines. Int J Infect Dis 2010, 14:e197-209.

3. Lin TY, Shah NK, Brooks D, Garcia CS: Summary of invasive pneumococcal disease burden among children in the Asia-Pacific region. Vaccine 2010, 28:7589-7605.

4. Gil-Prieto R, García-García L, Alvaro-Meca A, Méndez C, García A, de Miguel AG: The burden of hospitalisations for community-acquired pneumonia (CAP) and pneumococcal pneumonia in adults in Spain (2003-2007). Vaccine 2011, , 29: 412-416.

5. Centers for Disease Control and Prevention: Epidemiology and Prevention of Vaccine-Preventable Diseases. Washington DC: Public Health Foundation;i, 122011.

6. World Health Organization: Pneumococcal conjugate vaccine for childhood immunization - WHO position paper. Wkly Epidemiol Record 2007, 82:93-104.

7. Pneumococcal Disease Working Group: PneumoAware 2010. [http://www. pneumo.co.uk/Portals/0/Reports/ Burden_of_Disease_England_Pneumoaware_Report.pdf].

8. Jover F, Cuadrado JM, Andreu L, Martínez S, Cañizares R, de la Tabla VO, Martin C, Roig P, Merino J: A comparative study of bacteremic and nonbacteremic pneumococcal pneumonia. Eur J Intern Med 2008, 19:15-21.

9. World Health Organization: Pneumococcal vaccines. Wkly Epidemiol Record 2003, 14:110-19.

10. Levine OS, O'Brien KL, Knoll M, Adegbola RA, Black S, Cherian T, Dagan R, Goldblatt D, Grange A, Greenwood B, Hennessy T, Klugman KP, Madhi SA, Mulholland K, Nohynek H, Santosham M, Saha SK, Scott JA, Sow S, Whitney CG, Cutts F: Pneumococcal vaccination in developing countries. Lancet 2006, 367(9526):1880-1882.
11. Centers for Disease Control and Prevention: Vaccine preventable deaths and the global immunization vision and strategy, 2006-2015. MMWR Morb Mortal Wkly Rep 2006, 55:511-515.

12. Ministry of Health Malaysia: Health Facts 2009. 2010 [http://www.moh.gov. my/images/gallery/stats/heal_fact/healthfact-P_2009.pdf].

13. Prevenar Malaysian Package Insert. 2006.

14. Levine OS, Knoll MD, Jones A, Walker DG, Risko N, Gilani Z: Global status of Haemophilus influenzae type $b$ and pneumococcal conjugate vaccines: evidence, policies, and introductions. Curr Opin Infect Dis 2010, , 23: 236-241.

15. John TJ, Samuel R: Herd immunity and herd effect: new insights and definitions. Eur J Epidemiol 2000, 16:601-606.

16. Fox JP, Elveback L, Scott W, Gatewood L, Ackerman E: Herd Immunity: basic concept and relevance to public health immunization practices. Am J Epidemiol 1971, 94:179-189.

17. Plotkin S, Fine P, Eames K, Heyman DL: "Herd Immunity":A Rough Guide. Clin Infect Dis 2001, 52:911-916.

18. O'Brien KL, Dagan R: The potential Indirect effect of conjugate pneumococcal vaccine. Vaccine 2003, 21:1815-1825.

19. Centers for Disease Control and Prevention: Direct and Indirect Effects of Routine Vaccination of Children with 7-Valent Pneumococcal Conjugate Vaccine on Incidence of Invasive Pneumococcal Disease - United States, 1998-2003. MMWR Morb Mortal Wkly Rep 2005, 54:893-897.

20. Lexau CA, Lynfield R, Danila R, Pilishvili T, Facklam R, Farley MM, Harrison LH, Schaffner W, Reingold A, Bennett NM, Hadler J, Cieslak PR, Whitney CG, Active Bacterial Core Surveillance Team: Changing epidemiology of invasive pneumococcal disease among older adults in the era of pediatric pneumococcal conjugate vaccine. JAMA 2005, 294:2043-2051.

21. Metlay JP, Fishman NO, Joffe M, Edelstein PH: Impact of pediatric vaccination with pneumoccal conjugate vaccine on the risk of bacteremic pneumococcal pneumonia in adults. Vaccine 2006, 24:468-475.

22. McIntosh ED, Conway P, Willingham J, Lloyd A: The cost-burden of paediatric pneumococcal disease in the UK and the potential costeffectiveness of prevention using 7-valent pneumococcal conjugate vaccine. Vaccine 2003, 21:2564-2572.

23. Rudan I, Boschi-Pinto C, Biloglav Z, Mulholland K, Campbell H Epidemiology and etiology of childhood pneumonia. Bull World Health Organ 2008, 86:408-416.

24. Marcos MA, Martínez E, Almela M, Mensa J, Jiménez de Anta MT: New rapid antigen test for diagnosis of pneumococcal meningitis. Lancet 2001, 12:1499-1500.

25. Department of Statistics: Population and housing census statistics of Malaysia 20002001

26. Department of Statistics: Population distribution by authority areas and mukims. Population and housing census of Malaysia 2000.

27. Black S, Shinefield H, Fireman B, Lewis E, Ray P, Hansen JR, Elvin L, Ensor KM, Hackell J, Siber G, Malinoski F, Madore D, Chang I, Kohberger R, Watson W, Austrian R, Edwards K: Efficacy, safety and immunogenicity of heptavalent pneumococcal conjugate vaccine in children. Pediatr Infect Dis J 2000, 19:187-195.

28. Siti Norbaya M, Rohani MY, Nordiah AJ: Antimicrobial susceptibility pattern and serotype distribution among clinical isolates of Streptococcus pneumoniae in Malaysia [poster]. 4th Asian Congress of Pediatric Infectious Disease (ACPID) Surabaya, Indonesia; 2008.

29. Whitney CG, Farley MM, Hadler J, Harrison LH, Bennett NM, Lynfield R, Reingold A, Cieslak PR, Pilishvili T, Jackson D, Facklam RR, Jorgensen JH, Schuchat A: Active Bacterial Core Surveillance of the Emerging Infections Program Network: Decline in invasive pneumococcal disease after the introduction of protein-polysaccharide conjugate vaccine. N Engl J Med 2003, 348:1737-1746

30. World Health Organization: Abridged Life Table for Malaysian residents. 2008 [http://apps.who.int/ghodata/?vid = 60990].

31. Low S, Chan FL, Cutter J, Ma S, Goh KT, Chew SK: A national study of the epidemiology of pneumococcal disease among hospitalized patients in Singapore: 1995 to 2004. Singapore Med J 2007, 48:824-829.

32. Census and Statistics Department of Hong Kong: Death Statistics [http:// www.statistics.gov.hk/stat_table/population/D5320184BXXXXXXXXB.Xls].

33. World Health Organization: Making choices in health: WHO guide to costeffectiveness analysis Geneva: World Health Organization; 2003. 
34. International Monetary Fund: World Economic Outlook Database 2010 [http://www.imf.org/external/pubs/ft/weo/2010/02/weodata/index.aspx].

35. Whitney CG, Pilishvili T, Farley MM, Schaffner W, Craig AS, Lynfield R,

Nyquist AC, Gershman KA, Vazquez M, Bennett NM, Reingold A, Thomas A, Glode MP, Zell ER, Jorgensen JH, Beall B, Schuchat A: Effectiveness of seven-valent pneumococcal conjugate vaccine against invasive pneumococcal disease: a matched case-control study. Lancet 2006, 368:1495-1502.

36. Rückinger $S$, van der Linden $M$, Reinert RR, von Kries R: Efficacy of 7-valent pneumococcal conjugate vaccination in Germany: An analysis using the indirect cohort method. Vaccine 2010, 28:5012-5016.

37. Zhou F, Shefer A, Kong Y, Nuorti JP: Trends in acute otitis media-related health care utilization by privately insured young children in the United States, 1997-2004. Pediatrics 2008, 121:253-260.

38. World Health Organization: Cost-effectiveness Threshold Values [http://www. who.int/choice/costs/CER_thresholds/en/index.html].

39. Hooi LS, Lim TO, Goh A, Wong HS, Tan CC, Ahmad G, Morad Z: Economic evaluation of centre haemodialysis and continuous ambulatory peritoneal dialysis in Ministry of Health hospitals, Malaysia. Nephrology 2005, 10:25-32.

40. Isaacman DJ, Strutton DR, Kalpas EA, Horowicz-Mehler N, Stern LS, Casciano R, Ciuryla V: Impact of indirect (herd) protection on the costeffectiveness of pneumococcal conjugate vaccine. Clinical Therapeutics 2008, 30(8):341-357.

41. Talbot TR, Poehling KA, Hartert TV, Arbogast PG, Halasa NB, Mitchel E, Schaffner W, Craig AS, Edwards KM, Griffin MR: Reduction in high rates of antibiotic-nonsusceptible invasive pneumococcal disease in Tennessee after introduction of the pneumococcal conjugate vaccine. Clin Infect Dis 2004, 39:641-648.

\section{Pre-publication history}

The pre-publication history for this paper can be accessed here: http://www.biomedcentral.com/1471-2334/11/248/prepub

\section{Submit your next manuscript to BioMed Central and take full advantage of:}

- Convenient online submission

- Thorough peer review

- No space constraints or color figure charges

- Immediate publication on acceptance

- Inclusion in PubMed, CAS, Scopus and Google Scholar

- Research which is freely available for redistribution

Submit your manuscript at www.biomedcentral.com/submit 